\title{
Superiority of early relative to late ischemic preconditioning in spinal cord protection after descending thoracic aortic occlusion
}

Ioannis K. Toumpoulis, MDa

John C. Papakostas, MD

Miltiadis I. Matsagas, $\mathrm{MD}^{\mathrm{b}}$

Vassiliki D. Malamou-Mitsi, MD ${ }^{\mathrm{C}}$

Lina S. Pappa, MD ${ }^{\mathrm{c}}$

George E. Drossos, MD

Joseph J. DeRose, MD ${ }^{d}$

Constantine E. Anagnostopoulos, MD ${ }^{\mathrm{a}, \mathrm{d}}$

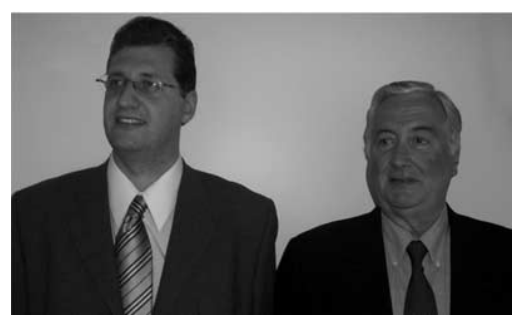

Drs Toumpoulis (left) and Anagnostopoulos (right)

Objective: We previously showed that ischemic preconditioning significantly reduced spinal cord injury caused by 35 -minute aortic occlusion. In this study we investigated the effect of ischemic preconditioning on spinal cord injury after 45-minute aortic occlusion.

Methods: Thirty-two pigs were divided as follows: group $1(\mathrm{n}=6)$ underwent sham operation, group $2(\mathrm{n}=6)$ underwent 20 minutes of aortic occlusion, group $3(\mathrm{n}=$ $6)$ underwent 45 minutes of occlusion, group $4(n=6)$ underwent 20 minutes of occlusion and 48 hours later underwent an additional 45 minutes, and group 5 ( $\mathrm{n}=$ 8 ) underwent 20 minutes of occlusion and 80 minutes later underwent an additional 45 minutes. Aortic occlusion was accomplished with two balloon occlusion catheters placed fluoroscopically after the origin of the left subclavian artery and at the aortic bifurcation. Neurologic evaluation was by Tarlov score. The lower thoracic and lumbar spinal cords were harvested at 120 hours and examined histologically with hematoxylin-eosin staining. The number of neurons was counted, and the inflammation was scored (0-4). Statistical analysis was by Kruskal-Wallis and 1-way analysis of variance tests.

From the Departments of Cardiothoracic Surgery, ${ }^{\text {a }}$ Surgery-Vascular Surgery Unit, ${ }^{\text {b }}$ and Pathology, ${ }^{\mathrm{c}}$ School of Medicine, University of Ioannina, Ioannina, Greece, and Columbia University College of Physicians and Surgeons, St Luke's-Roosevelt Hospital Center, New York, NY. ${ }^{d}$

Supported by a grant from St Jude Medical/ Hellas Corporation, Michailidion Foundation and Ioannina Biomedical Institute, Unit of Medical Technology and Intelligent Information Systems, University of Ioannina, Greece.

Read at the Eighty-fourth Annual Meeting of The American Association for Thoracic Surgery, Toronto, Ontario, Canada, April 25-28, 2004.

Received for publication April 23, 2004; revisions received June 7, 2004; accepted for publication June 23, 2004.

Address for reprints: Constantine E. Anagnostopoulos, MD, St. Luke's-Roosevelt Hospital Center at Columbia University, 45 E 89th St, New York, NY 10128 (E-mail: cea8@columbia.edu)

J Thorac Cardiovasc Surg 2004;128:724-30 $0022-5223 / \$ 30.00$

Copyright (C) 2004 by The American Association for Thoracic Surgery

doi:10.1016/j.jtcvs.2004.06.031

Results: Group 5 (early ischemic preconditioning) had better Tarlov scores than group $3(P<.001)$ and group 4 (late ischemic preconditioning, $P<.001)$. The histologic changes were proportional to the Tarlov scores, with the least histologic damage in the animals of group 5 relative to group 3 (number of neurons $P<.001$, inflammation $P=.004$ ) and group 4 (number of neurons $P<.001$, inflammation $P=.006)$.

Conclusion: Early ischemic preconditioning is superior to late ischemic preconditioning in reducing spinal cord injury caused by the extreme ischemia of 45 minutes of descending thoracic aortic occlusion.

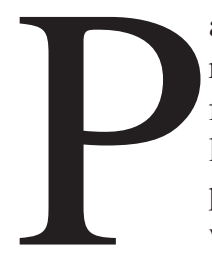
araplegia remains a devastating complication after thoracic and thoracoabdominal aortic operations. The incidence of neurologic injury from such operations ranges from $3 \%$ to $16 \%{ }^{1-3}$ in the largest published clinical series. Spinal cord injury is even more frequent among patients who need extent II thoracoabdominal aortic aneurysm repair, with paraplegia and paraparesis rates ranging from $5 \%$ to $32 \% .^{2-4}$ Numerous surgical ${ }^{1-4}$ and pharmacologic ${ }^{5}$ approaches have been tried both clinically and experimentally in an attempt to prevent paraplegia, but no randomized 
studies have clearly confirmed a single clinical intervention to effect this goal. Ischemic preconditioning (IPC) is a novel strategy for spinal cord protection after aortic occlusion. IPC is the process whereby a brief ischemic episode enhances the tolerance of the tissue to a subsequent lethal ischemic insult. There are two types of IPC. Early IPC induces ischemic tolerance in minutes to hours after brief ischemia, whereas late IPC requires days to induce its beneficial effect. These two types of IPC have been documented for spinal cord protection after aortic occlusion, especially in small animal models. ${ }^{6-9}$

We previously showed that both early and late IPC significantly reduced spinal cord injury caused by 35minute descending thoracic aortic occlusion (DTAO) in a porcine experimental model. ${ }^{10,11}$ The purpose of this study was to determine and compare the effects of early and late IPC on spinal cord injury caused by the extreme ischemia of 45-minute DTAO in the same large-mammal animal model.

\section{Material and Methods Experimental Protocol}

A total of 32 pigs of either sex were used in this study. All animals weighed between 28 and $32 \mathrm{~kg}$ and were randomly assigned to one of five groups. Group $1(\mathrm{n}=6)$ underwent a sham operation, group $2(\mathrm{n}=6)$ underwent DTAO for 20 minutes, group $3(\mathrm{n}=6)$ underwent DTAO for 45 minutes, group $4(\mathrm{n}=6)$ underwent DTAO for 20 minutes and 48 hours later DTAO for 45 minutes, and group $5(\mathrm{n}=8)$ underwent DTAO for 20 minutes and 80 minutes later DTAO for 45 minutes. All animals received humane care in compliance with the "Guide for the Care and Use of Laboratory Animals" (http://www.nap.edu/catalog/5140.html). The animal protocol was approved by the Institutional Animal Care and Use Committee of the University of Ioannina, Ioannina, Greece.

\section{Experimental Preparation}

All animals fasted for 12 hours before the procedure. The pigs were anesthetized with intramuscular injection of azaperone (4 $\mathrm{mg} / \mathrm{kg}$ ) and, after 20 minutes, ketamine hydrochloride $(5-10 \mathrm{mg} /$ $\mathrm{kg}$ ). Catheters were placed in two ear veins for intravenous administration of general anesthesia and fluids. General anesthesia consisted of $2.5 \%$ thiopental sodium at 10 to $15 \mathrm{mg} / \mathrm{kg}$, and the animals were tracheally intubated and given intravenous ketamine hydrochloride (1-2 mg/kg), atracurium besylate $(0.4-0.6 \mathrm{mg} / \mathrm{kg}$ and $0.1 \mathrm{mg} / \mathrm{kg}$ every $20-30$ minutes), fentanyl citrate $(1.5-8 \mu \mathrm{g} /$ $\mathrm{kg}$ ), and gentamicin sulfate $(1 \mathrm{mg} / \mathrm{kg})$. General anesthesia was maintained with $1 \%$ to $3 \%$ sevoflurane, depending on the phase of the experiment. The pigs' lungs were ventilated with $100 \%$ oxygen with the $\mathrm{PaO}_{2}$ maintained greater than $100 \mathrm{~mm} \mathrm{Hg}, \mathrm{PaCO}_{2}$ maintained at 35 to $45 \mathrm{~mm} \mathrm{Hg}$, and $\mathrm{pH}$ maintained at normal levels, as confirmed by arterial blood gas analysis. All animals were placed on a warming blanket, and rectal temperature was maintained at $36.0^{\circ} \mathrm{C}$ to $37.1^{\circ} \mathrm{C}$. Electrocardiograms were continuously recorded with needle electrodes.

Under sterile conditions, the right femoral artery, left jugular vein, and left common carotid artery were isolated. After the intravenous administration of heparin (300 IU/kg), catheters were inserted. Continuous monitoring and recording of the proximal and distal arterial pressures, as well as pulmonary arterial pressure, were performed. Systolic arterial pressure was maintained greater than $100 \mathrm{~mm} \mathrm{Hg}$, and blood $(7 \mathrm{~mL} / \mathrm{kg}$ ) was drained into a citrate bag for collection.

In this experimental model, the DTAO was performed with two 9F aortic balloon occlusion catheters (occlusion balloon catheters; Medi-tech Boston Scientific, Boston, Mass), which were inserted with fluoroscopic guidance. The first was inserted through the carotid artery to the descending thoracic aorta and pulled up toward the carotid artery to achieve DTAO after the origin of the left subclavian artery when inflated. The second balloon was inserted through the femoral artery to the aortic bifurcation (trifurcation in the pig) and the common iliac arteries (to avoid retrograde flow). During DTAO and 1 hour after the blood flow restoration, the heart rate, arterial pressures (proximal, isolated aortic segment, and distal), and rectal temperature were recorded every 5 minutes. After DTAO (in groups 2, 3, 4, and 5), the balloons were deflated and all animals were fully resuscitated with intravenous fluids (lactated Ringer solution) and the reinfusion of autologous blood. Sodium bicarbonate $(1 \mathrm{mEq} / \mathrm{kg})$ was administered to restore acid-base status, and blood pressure was restored with phenylephrine hydrochloride (0.1-0.2 $\mathrm{mg}$ in bolus infusion during the first minutes after blood flow restoration). After 60 minutes of reperfusion, all the animals were in hemodynamically stable condition (systolic blood pressure $>105 \mathrm{~mm} \mathrm{Hg}$ ), without any need for fluid or drug administration. All the catheters were removed, and all the wounds were closed. When the pig was breathing spontaneously, the trachea was extubated, and another dose of gentamicin sulfate $(1 \mathrm{mg} / \mathrm{kg})$ was administered intravenously. Finally, the animals were placed in their cages for postoperative care and follow-up.

Animals in group 1 (sham operation) underwent the described procedure except that the balloons were not inflated. In group 2, there was inflation for 20 minutes only. In group 3, there was inflation for 45 minutes without IPC. In group 4 (late IPC), we performed two aortic occlusions with a reperfusion interval of 48 hours between. In group 5 (early IPC), the reperfusion interval between occlusions was 80 minutes. Before each DTAO, blood was taken from the animals for the two autologous reinfusions. During the reperfusion interval of 80 minutes in group 5 and at least 60 minutes after 20 minutes of DTAO in group 4 (after this point the animals were in hemodynamically stable condition without any need for fluid or drug administration), the systolic arterial blood pressure was maintained greater than $100 \mathrm{~mm} \mathrm{Hg}$.

\section{Neurologic Evaluation}

At 24, 48, and 120 hours after the end of the experiment, all animals were evaluated by an independent observer and graded according to the Tarlov scoring system ${ }^{12}$ (0 representing spastic paraplegia and no movement of the lower limbs, 1 representing spastic paraplegia and slight movement of the lower limbs, 2 representing good movement of the lower limps but inability to stand, 3 representing ability to stand but inability to walk normally, and 4 representing complete recovery). 
Table 1. Proximal systolic arterial pressure and heart rate at baseline, during DTAO, and during reperfusion in groups 4 and 5 during the first DTAO (20 minutes) and the second DTAO (45 minutes)

\begin{tabular}{|c|c|c|c|c|c|c|}
\hline & \multicolumn{2}{|c|}{ Baseline } & \multicolumn{2}{|c|}{ DTAO } & \multicolumn{2}{|c|}{ Reperfusion } \\
\hline & $\begin{array}{c}\text { Proximal SAP } \\
(\mathrm{mm} \mathrm{Hg})\end{array}$ & $\begin{array}{l}\text { Heart rate } \\
\text { (beats/min) }\end{array}$ & $\begin{array}{c}\text { Proximal SAP } \\
(\mathrm{mm} \mathrm{Hg})\end{array}$ & $\begin{array}{c}\text { Heart rate } \\
\text { (beats/min) }\end{array}$ & $\begin{array}{l}\text { Proximal SAP } \\
(\mathbf{m m ~ H g})\end{array}$ & $\begin{array}{c}\text { Heart rate } \\
\text { (beats/min) }\end{array}$ \\
\hline \multicolumn{7}{|l|}{ Group 4} \\
\hline First DTAO (20 min) & $109 \pm 6$ & $92 \pm 9$ & $177 \pm 9$ & $173 \pm 14$ & $111 \pm 7$ & $124 \pm 20$ \\
\hline Second DTAO (45 $\mathrm{min})$ & $107 \pm 4$ & $96 \pm 7$ & $175 \pm 8$ & $176 \pm 11$ & $109 \pm 7$ & $127 \pm 17$ \\
\hline$P$ value & 439 & .432 & .287 & 381 & .143 & .452 \\
\hline \multicolumn{7}{|l|}{ Group 5} \\
\hline First DTAO (20 min) & $106 \pm 3$ & $90 \pm 8$ & $179 \pm 10$ & $176 \pm 14$ & $109 \pm 7$ & $122 \pm 20$ \\
\hline Second DTAO (45 $\mathrm{min})$ & $108 \pm 5$ & $95 \pm 10$ & $160 \pm 9$ & $158 \pm 11$ & $107 \pm 6$ & $120 \pm 19$ \\
\hline$P$ value & .394 & .296 & $<.001$ & $<.001$ & .125 & .548 \\
\hline
\end{tabular}

All values mean \pm SD. Statistical analysis was by means of paired samples $t$ test. SAP, Systolic arterial blood pressure.

\section{Histologic Study}

The animals were killed 120 hours after the end of the experiment with an overdose injection of sodium pentobarbital, and spinal cords specimens were harvested immediately for histologic study by means of light microscopy. The lower thoracic and lumbar spinal cords were fixed in $10 \%$ formalin solution for 120 hours before being set in paraffin blocks for sectioning. Three representative glass slices with $7-\mu \mathrm{m}$ thick sections were obtained from each animal at L1 and stained with hematoxylin-eosin. A pathologist unaware of the pig's neurologic outcome examined each slice by means of light microscopy to count the total number of motor neurons in the gray matter half of each slice. The grade of inflammation was scored from 0 to 4 (very high grade of inflammation with very high vascularization with hyperemia scored 0 , high grade of inflammation with high vascularization with hyperemia scored 1, moderate inflammation with moderate vascularization with or without hyperemia scored 2 , low inflammation with moderate vascularization with or without hyperemia scored 3 , and no inflammation with normal vascularization without hyperemia scored 4).

\section{Statistical Analysis}

Data are presented as mean \pm SD. Statistical evaluation was performed by 1-way analysis of variance test with the post hoc Tukey honestly significant difference test for comparison of experimental variables between groups. The comparison of experimental variables within a group used paired samples $t$ test. The differences among groups in terms of the Tarlov scores and the grade of inflammation were determined by nonparametric statistical analysis with the Kruskal-Wallis test, whereas differences between two groups were determined with the Mann-Whitney $U$ test. SPSS version 11.0 software (SPSS Inc, Chicago, Ill) was used for statistical analyses.

\section{Results}

\section{Hemodynamic Measurements}

The animals did not differ with respect to blood gas analysis. There were no significant differences among groups 2 , 3,4 , and 5 with regard to systolic arterial pressure (proximal and distal), rectal temperature, and heart rate at baseline, during DTAO, and during reperfusion. Between group 1 and groups 2, 3, 4, and 5 there were significant differences in heart rate and systolic arterial pressure (proximal and distal) during DTAO $(P<.001)$. There was no significant difference in aortic isolated segment pressure among groups 2, 3, 4, and 5 (mean aortic isolated pressure $14 \mathrm{~mm} \mathrm{Hg}$ ). Table 1 shows that the systolic arterial pressure proximal to DTAO and the heart rate in the early IPC group 5 were significantly depressed during the second DTAO of 45 minutes relative to the first DTAO of 20 minutes. This reduction in arterial blood pressure was not present in the late IPC group (group 4).

\section{Neurologic Outcome}

The neurologic results are summarized in Table 2. All animals in groups 1 and 2 had normal neurologic outcome (Tarlov score 4) at 24, 48, and 120 hours. In group 3, 1 animal had a Tarlov score of 2 at 24 hours, 3 animals had a score of 1 , and 2 animals had a score of 0 ; at 48 hours, 3 animals had a score of 1 , and 3 animals had a score of 0 ; and at 120 hours, 2 animals had a score of 1, and 4 animals had a score of 0 . In group 4 (late IPC), 2 animals had a Tarlov score of 2 at 24 hours, 3 animals had a score of 1 , and 1 animal had a score of 0 ; at 48 hours, 1 animal had a score of 2, 3 animals had a score of 1 , and 2 animals had a score of 0 ; and at 120 hours, 1 animal had a score of 2, 2 animals had a score of 1 , and 3 animals had a score of 0 . In group 5 (early IPC), 6 animals had a Tarlov score of 4 at 24 hours, and 2 animals had a score of 3; at 48 hours, 5 animals had a score of 4 , and 3 animals had a score of 3; and at 120 hours, 5 animals had a score of 4 and 3 animals had a score of 3 .

Significant differences were seen in neurologic outcome between group 5 and groups 3 and group 4 at 24, 48, and 120 hours $(P<.001)$. An aggravation of the mean Tarlov scores in groups 3, 4, and 5 was seen in comparing the results at 24 and 120 hours after the end of experiment, but 
Table 2. Tarlov scores at 24,48 , and 120 hours after the end of the experiment

\begin{tabular}{lccc}
\hline & $\mathbf{2 4} \mathbf{h}$ & $\mathbf{4 8} \mathbf{~ h}$ & $\mathbf{1 2 0} \mathbf{~ h}$ \\
\hline Group $1(\mathrm{n}=6$, sham operation) & $4.00 \pm 0.00$ & $4.00 \pm 0.00$ & $4.00 \pm 0.00$ \\
Group 2 $(\mathrm{n}=6,20$ min DTAO) & $4.00 \pm 0.00$ & $4.00 \pm 0.00$ & $4.00 \pm 0.00$ \\
Group 3 $(\mathrm{n}=6,45$ min DTA0) & $0.83 \pm 0.75$ & $0.50 \pm 0.55$ & $0.33 \pm 0.52$ \\
Group 4 $(\mathrm{n}=6$, late IPC) & $1.17 \pm 0.75$ & $0.83 \pm 0.75$ & $0.67 \pm 0.82$ \\
Group 5 (n=8, early IPC) & $3.75 \pm 0.46$ & $3.63 \pm 0.52$ & $3.63 \pm 0.52$ \\
$P$ value & $<.001$ & $<.001$ & $<.001$ \\
\hline
\end{tabular}

All values mean \pm SD. Statistical analysis was by means of the nonparametric Kruskal-Wallis test.

this aggravation was not statistically significant $(P=.083$, $P=.083$, and $P=.317$ respectively, Wilcoxon test).

\section{Histologic Evaluation}

The results of neuron counting in the gray matter half of each slice are shown in Table 3. According to the scoring system, animals in groups 3 and 4 had the worst scores (31 \pm 6 motor neurons and $1.33 \pm 0.82$ inflammation score, 47 \pm 17 motor neurons and $1.50 \pm 0.84$ inflammation score, respectively). Groups 1 and 2 had normal scores (171 \pm 8 motor neurons and $4.00 \pm 0.00$ inflammation score, $167 \pm$ 7 motor neurons and $4.00 \pm 0.00$ inflammation score, respectively). In group 5 (early IPC) there were a preservation of the number of neurons and a reduction in the grade of inflammation (136 \pm 34 motor neurons and $3.38 \pm 0.92$ inflammation score) relative to group $3(P<.001$ for number of neurons with post hoc multiple comparisons tests that used the Tukey honestly significant difference and $P=$ .005 for inflammation score with Mann-Whitney $U$ test) and group 4 ( $P<.001$ for number of neurons and $P=.008$ for inflammation score). The reduction of about $20 \%$ in the number of neurons that was observed in the early IPC group (group 5) was statistically significantly different from that in group $1(P=.019)$ and group $2(P=.045)$. The reduction of about $70 \%$ in the number of neurons in group 4 (late IPC) was not statistically significantly different from that in group $3(P=.589)$. Representative photographs of spinal cord sections are shown in Figures 1 and 2.

\section{Discussion}

Previous reports of small animal models have shown beneficial effects of both late and early IPC against spinal cord injury, ${ }^{6-9}$ and we previously demonstrated this in a porcine model after 35-minute DTAO. ${ }^{10,11}$ It is also known that in one of the largest clinical series of thoracoabdominal aneurysm repair, the mean time of aortic occlusion was 43 minutes. ${ }^{3}$ In this study, we evaluated separately the effects of early and late IPC on spinal cord injury after 45-minute DTAO, which simulated extent II thoracoabdominal aortic aneurysm repair. We found that only early IPC, without hypotension during the reperfusion period, significantly reduced spinal cord injury. Although complete protection was
Table 3. Number of motor neurons in the gray matter half and grade of inflammation

\begin{tabular}{lcc}
\hline & No. of neurons & $\begin{array}{c}\text { Inflammation } \\
\text { grade }\end{array}$ \\
\hline Group $1(\mathrm{n}=6$, sham operation) & $171 \pm 8$ & $4.00 \pm 0.00$ \\
Group $2(\mathrm{n}=6,20$ min DTAO) & $167 \pm 7$ & $4.00 \pm 0.00$ \\
Group 3 $(\mathrm{n}=6,45$ min DTA0) & $31 \pm 6$ & $1.33 \pm 0.82$ \\
Group $4(\mathrm{n}=6$, late IPC) & $47 \pm 17$ & $1.50 \pm 0.84$ \\
Group 5 $(\mathrm{n}=8$, early IPC) & $136 \pm 34$ & $3.38 \pm 0.92$ \\
$P$ value & $<.001$ & $<.001$
\end{tabular}

All values mean \pm SD. Statistical analysis was by means of 1-way analysis of variance test for the number of neurons and nonparametric KruskalWallis test for the grade of inflammation.

not achieved in our study, the animals in the early IPC group (group 5) had a mean Tarlov score of 3.63 at 120 hours, and we observed no animal with a Tarlov score lower than 3 . A Tarlov score of 3 means that the animal is able to stand and walk, whereas a Tarlov score of 2 means that the animal is unable to stand, and this represents a fundamental difference.

The porcine model is a widely accepted model for investigating different strategies of spinal cord protection, and this model could also be important in verifying safety and efficacy of protective adjuncts designed for clinical use. Most studies agree that paraplegia in the pig model occurs if the duration of normothermic DTAO equals or exceeds 30 minutes. ${ }^{13,14}$ Thus the 45 -minute DTAO used in this study represents an extreme ischemic insult, as confirmed by group 3 (almost all the animals showed complete paraplegia at 120 hours). The median sacral artery in pigs provides a significant amount of flow to the lower spinal cord, and this artery has to be considered important in such experiments. ${ }^{15}$ That was why we used two balloon occlusion catheters, one after the origin of the left subclavian artery and one at the aortic bifurcation (trifurcation in pig, with two iliac arteries and median sacral artery) to avoid retrograde flow. Spinal cord perfusion pressure is equal to the mean arterial pressure minus the cerebrospinal fluid pressure. ${ }^{16}$ Clinical studies $^{1}$ and experimental studies in pigs ${ }^{16}$ have shown that the mean normal cerebrospinal fluid pressure is between 10 and $13 \mathrm{~mm} \mathrm{Hg}$, with an increase during DTAO. ${ }^{1}$ Thus the mean 


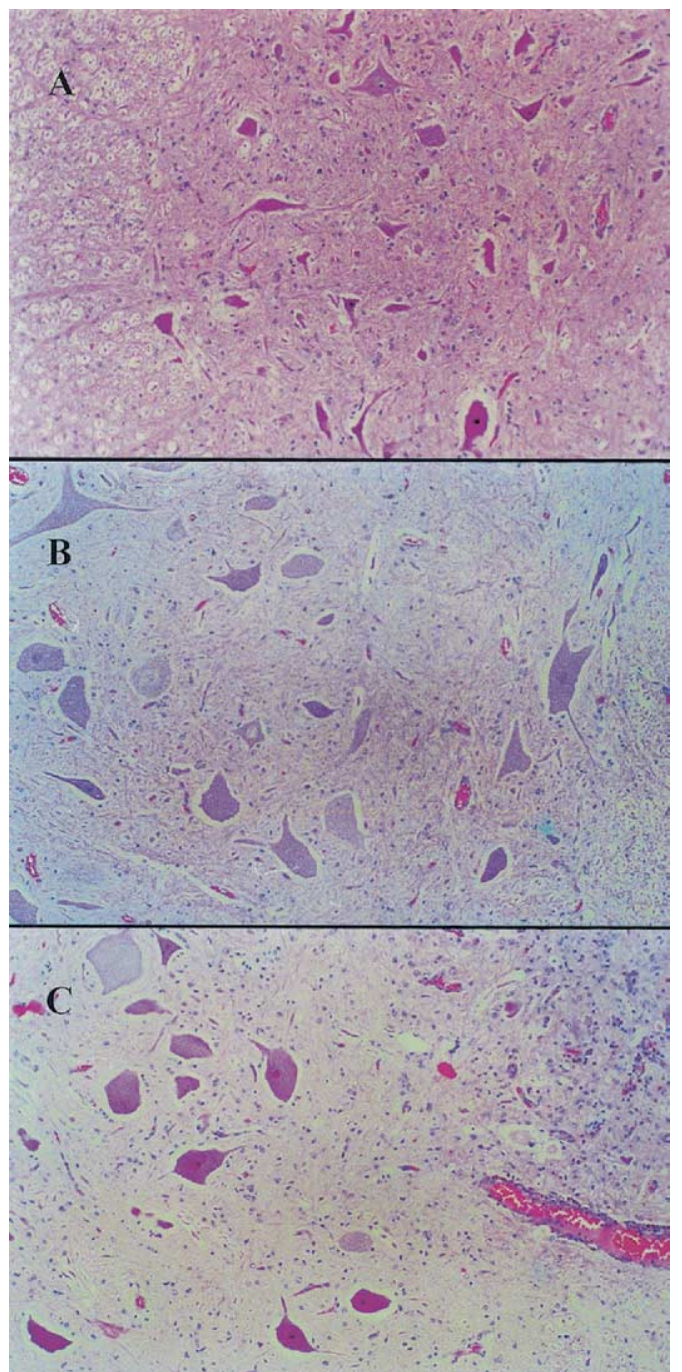

Figure 1. Representative photomicrographs of lumbar spinal cord sections stained with hematoxylin-eosin (original magnification $\times 330$ ). No neuronal damage to any motor neuron cells was found in animals of group 1 undergoing sham operation (A) and group 2 undergoing 20 minutes of DTAO (B). At 120 hours after $\mathbf{4 5}$ minutes of ischemia, motor neuron cells in early IPC group 5 were preserved (C).

aortic isolated pressure of $14 \mathrm{~mm} \mathrm{Hg}$ in our study was inadequate to perfuse the spinal cord. We also ruled out the effects of hypothermia and hypotension, because all groups with DTAO had similar rectal temperatures and blood pressure during DTAO and during reperfusion.

The beneficial effects of early IPC on spinal cord injury have been confirmed by other investigators. ${ }^{78}$ However, some reports have shown no protective effect or only transient protection. ${ }^{17,18}$ Kakimoto and colleagues ${ }^{18}$ showed in a rabbit model that the protective efficacy of early IPC was no longer apparent at 7 days after reperfusion. In our study all animals were followed up for 120 hours, and there was

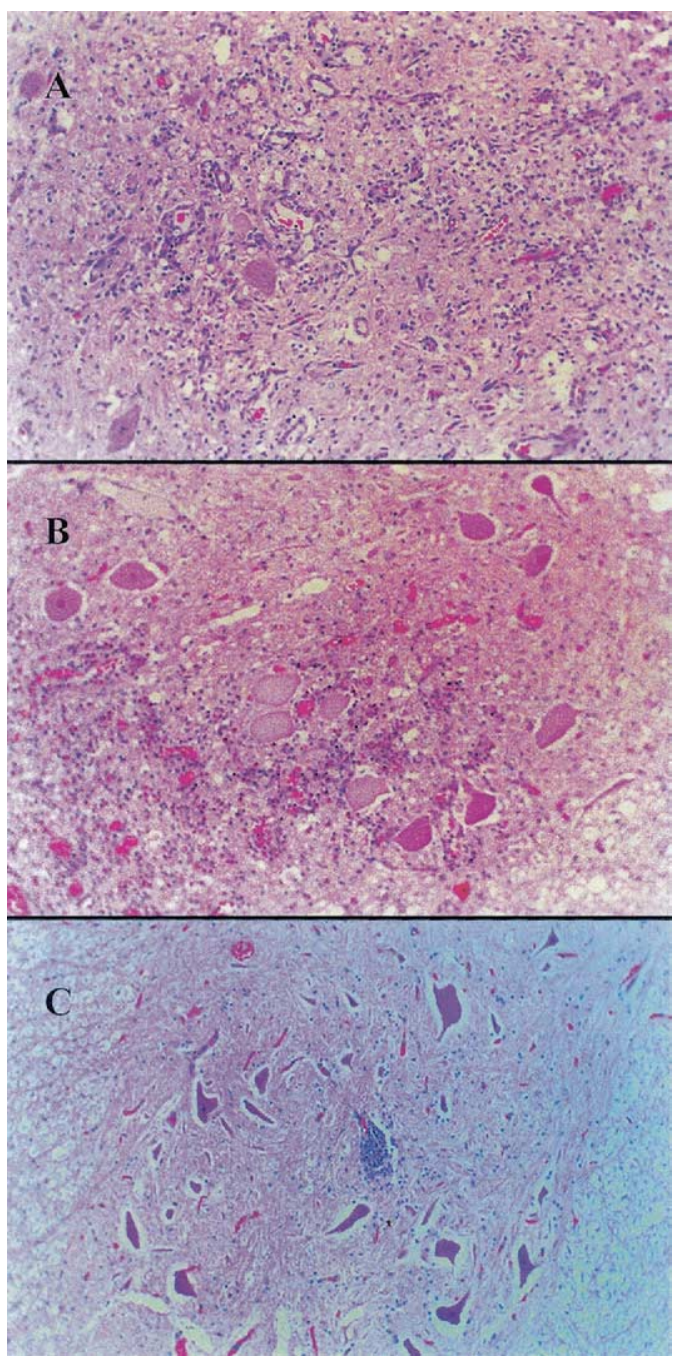

Figure 2. Representative photomicrographs of lumbar spinal cord sections stained with hematoxylin-eosin (original magnification $\times 330$ ). At 120 hours after 45 minutes of descending thoracic aortic occlusion, approximately $\mathbf{8 0} \%$ of motor neuron cells were lost in gray matter in untreated group 3 (A), and approximately $70 \%$ of motor neuron cells were lost in late IPC group 4 (B), with inflammatory infiltration obvious in both groups. In contrast, there was only $20 \%$ reduction of motor neuron cells in early IPC group 5, with inflammation significantly reduced (C).

no aggravation in their neurologic outcome after 48 hours of reperfusion. If the animals had hypotension during the 80minute reperfusion, however, the protective effect of IPC was abolished. ${ }^{10,19}$ Maintenance of the systolic arterial blood pressure at baseline levels during reperfusion may be an important factor if early IPC is to provide spinal cord protection, and it is not clear whether this occurred in the studies that showed no or transient protection. ${ }^{20,21}$

Mechanisms by which IPC can protect the spinal cord at an early point after ischemic injury have not been well 
elucidated. Inflammatory cascades start immediately after the ischemic insult, and spinal cord injury can be prevented by the administration of leukocyte antiadhesion molecules. $^{22}$ We showed clearly that early IPC significantly reduced the grade of inflammation relative to late IPC, and this modulation of the inflammatory process may be part of its superior protective effect. Adenosine, ${ }^{14}$ adenosine agonists, ${ }^{23}$ and mitochondrial adenosine triphosphate-sensitive potassium channels ${ }^{17}$ may be involved in the promotion of ischemic tolerance by early IPC. Another possible mechanism that may provide protection after the brief ischemic insult is the downregulation of the N-methyl-D-aspartate receptors during the acute postreflow phase after IPC. ${ }^{24}$

Early and late IPC share common mechanisms (same initial insult), but they also have significant differences. The significant reduction in proximal systolic arterial blood pressure and in heart rate during the second DTAO of 45 minutes in early IPC group 5 was also noted in other studies. ${ }^{8,10}$ A proposed explanation has been given by Miyamoto and associates, ${ }^{25}$ involving the protective $\beta$-amino acid taurine. Another important distinction is that although early IPC does not require production of new proteins, delayed IPC does. ${ }^{9,26}$ Cizkova and colleagues ${ }^{27}$ showed in a rat model that early IPC (3 minutes of IPC, 30 minutes of reperfusion, 10 minutes of DTAO) reduced spinal cord injury at 7 days, whereas late IPC (3 minutes of IPC, 24 hours of reperfusion, 10 minutes of DTAO) provided only partial recovery, thus confirming the superiority of early IPC. They also found by using microarrays that in the early IPC group there was a rapid induction of the transcription factors early growth response 1 and mitogen-activated protein kinase phosphatase ptpn16, and the known function of these genes identifies them as possible regulatory genes that may affect downstream changes. ${ }^{28}$ This knowledge may be the key element in developing pharmacologic preconditioning for a successful use in patients undergoing aortic crossclamping, because IPC also showed protection in the porcine model, which is close to the clinical situation.

\section{Study Limitations}

Balloon occlusion of the thoracic aorta as used in these experiments may have had a beneficial effect on spinal cord perfusion because the occlusion of the intercostal and lumbar arteries contributed to avoid steal phenomena. However, all the animals in group 3 were almost complete paraplegic. In addition, balloon occlusion makes the surgical procedure simple and is more quickly accomplished and less invasive than aortic crossclamping through a thoracotomy. Another limitation is the duration of brief ischemia and the duration of the reperfusion interval. The brief ischemia of 20 minutes may be considered prolonged; however it was well-tolerated in all animals in groups 2, 3, 4, and 5. In terms of the reperfusion interval, additional studies are needed to reveal the best reperfusion interval for preconditioning the spinal cord. Finally, in our study it was of great importance to maintain the systolic arterial blood pressure at greater than $100 \mathrm{~mm} \mathrm{Hg}$ during the reperfusion interval of 80 minutes between the two DTAOs. Nevertheless, it is well known that hypotension should be avoided during normothermic DTAO, and our protocol specifically excluded experiments in which hypotension occurred.

\section{Conclusion}

We used a porcine experimental model to show that early IPC is superior to late IPC in reducing spinal cord injury even after an extreme normothermic ischemia of 45-minute DTAO, which simulates extent II thoracoabdominal aneurysm repair. However, it may be necessary to use further combined therapeutic methods for complete prevention of ischemic neuronal injury.

We thank Dimitrios Athanasoulas, RN, for his excellent technical assistance in preparing this experimental model.

\section{References}

1. Cambria RP, Davison JK, Zannetti S, L'Italien G, Brewster DC, Gertler JP, et al. Clinical experience with epidural cooling for spinal cord protection during thoracic and thoracoabdominal aneurysm repair. J Vasc Surg. 1997;25:234-41.

2. Safi HJ, Miller CC 3rd, Huynh TT, Estrera AL, Porat EE, Winnerkvist AN, et al. Distal aortic perfusion and cerebrospinal fluid drainage for thoracoabdominal and descending thoracic aortic repair: ten years of organ protection. Ann Surg. 2003;238:372-80.

3. Svensson LG, Crawford ES, Hess KR, Coselli JS, Safi HJ. Experience with 1509 patients undergoing thoracoabdominal aortic operations. $J$ Vasc Surg. 1993;17:357-68.

4. Coselli JS. The use of left heart bypass in the repair of thoracoabdominal aortic aneurysms: current techniques and results. Semin Thorac Cardiovasc Surg. 2003;15:326-32.

5. Reece TB, Kern JA, Tribble CG, Cassada DC. The role of pharmacology in spinal cord protection during thoracic aortic reconstruction. Semin Thorac Cardiovasc Surg. 2003;15:365-77.

6. Abraham VS, Swain JA, Forgash AJ, Williams BL, Musulin MM. Ischemic preconditioning protects against paraplegia after transient aortic occlusion in the rat. Ann Thorac Surg. 2000;69:475-9.

7. Sirin BH, Ortac R, Cerrahoglu M, Saribulbul O, Baltalarli A, Celebisoy $\mathrm{N}$, et al. Ischaemic preconditioning reduces spinal cord injury in transient ischaemia. Acta Cardiol. 2002;57:279-85.

8. Zvara DA, Colonna DM, Deal DD, Vernon JC, Gowda M, Lundell JC. Ischemic preconditioning reduces neurologic injury in a rat model of spinal cord ischemia. Ann Thorac Surg. 1999;68:874-80.

9. Sakurai M, Hayashi T, Abe K, Aoki M, Sadahiro M, Tabayashi K. Enhancement of heat shock protein expression after transient ischemia in the preconditioned spinal cord of rabbits. J Vasc Surg. 1998;27:720-5.

10. Toumpoulis IK, Anagnostopoulos CE, Drossos GE, Malamou-Mitsi VD, Pappa LS, Katritsis DG. Early ischemic preconditioning without hypotension prevents spinal cord injury caused by descending thoracic aortic occlusion. J Thorac Cardiovasc Surg. 2003;125:1030-6.

11. Toumpoulis IK, Anagnostopoulos CE, Drossos GE, Malamou-Mitsi VD, Pappa LS, Katritsis DG. Does ischemic preconditioning reduce spinal cord injury because of descending thoracic aortic occlusion? $J$ Vasc Surg. 2003;37:426-32.

12. Tarlov IM. Spinal cord compression: mechanisms of paralysis and treatment. Springfield (IL): Charles C Thomas; 1957. p. 147.

13. Qayumi AK, Janusz MT, Dorovini-Zis K, Lyster DM, Jamieson WR, Poostizadeh A, et al. Additive effect of allopurinol and deferoxamine 
in the prevention of spinal cord injury caused by aortic crossclamping. J Thorac Cardiovasc Surg. 1994;107:1203-9.

14. Ross SD, Kern JA, Gangemi JJ, St Laurent CR, Shockey KS, Kron IL, et al. Hypothermic retrograde venous perfusion with adenosine cools the spinal cord and reduces the risk of paraplegia after thoracic aortic clamping. J Thorac Cardiovasc Surg. 2000;119:588-95.

15. Strauch JT, Spielvogel D, Lauten A, Zhang N, Shiang H, Weisz D, et al. Importance of extrasegmental vessels for spinal cord blood supply in a chronic porcine model. Eur J Cardiothorac Surg. 2003;24:817-24.

16. de Haan P, Kalkman CJ, Meylaerts SA, Lips J, Jacobs MJ. Development of spinal cord ischemia after clamping of noncritical segmental arteries in the pig. Ann Thorac Surg. 1999;68:1278-84.

17. Caparrelli DJ, Cattaneo SM, Bethea BT, Shake JG, Eberhart C, Blue ME, et al. Pharmacological preconditioning ameliorates neurological injury in a model of spinal cord ischemia. Ann Thorac Surg. 2002;74:838-44.

18. Kakimoto M, Kawaguchi M, Sakamoto T, Inoue S, Furuya H, Nakamura M, et al. Evaluation of rapid ischemic preconditioning in a rabbit model of spinal cord ischemia. Anesthesiology. 2003;99:1112-7.

19. Toumpoulis IK. The role of ischemic preconditioning in spinal cord protection after descending thoracic aortic occlusion [thesis]. Ioannina, Greece. University of Ioannina, School of Medicine; 2003.

20. Toumpoulis IK. The role of early ischemic preconditioning in spinal cord protection after transient aortic occlusion. Eur J Cardiothorac Surg. 2003;24:851-2.

21. Toumpoulis IK, Anagnostopoulos CE. Early ischemic preconditioning for spinal cord protection. Ann Thorac Surg. 2003;76:1340-1.

22. Naidu KA, Fu ES, Sutton ET, Prockop LD, Cantor A. The therapeutic effects of epidural intercellular adhesion molecule-1 monoclonal antibody in a rabbit model: involvement of the intercellular adhesion molecule-1 pathway in spinal cord ischemia. Anesth Analg. 2003;97:857-62.

23. Cassada DC, Tribble CG, Long SM, Laubach VE, Kaza AK, Linden J, et al. Adenosine A2A analogue ATL-146e reduces systemic tumor necrosing factor-alpha and spinal cord capillary platelet-endothelial cell adhesion molecule-1 expression after spinal cord ischemia. $J$ Vasc Surg. 2002;35:994-8.

24. Lee JM, Grabb MC, Zipfel GJ, Choi DW. Brain tissue responses to ischemia. J Clin Invest. 2000;106:723-31.

25. Miyamoto TA, Miyamoto KJ. Mechanisms of acute ischemic preconditioning. Ann Thorac Surg. 2000;70:2186.

26. Matsuyama K, Chiba Y, Ihaya A, Kimura T, Tanigawa N, Muraoka R. Effect of spinal cord preconditioning on paraplegia during crossclamping of the thoracic aorta. Ann Thorac Surg. 1997;63:1315-20.

27. Cizkova D, Carmel JB, Yamamoto K, Kakinohana O, Sun D, Hart RP, et al. Characterization of spinal HSP72 induction and development of ischemic tolerance after spinal ischemia in rats. Exp Neurol. 2004;185: 97-108.

28. Carmel JB, Kakinohana O, Mestril R, Young W, Marsala M, Hart RP. Mediators of ischemic preconditioning identified by microarray analysis of rat spinal cord. Exp Neurol. 2004;185:81-96.

\section{Discussion}

Dr Frank A. Pigula (Boston, Mass). In your groups 3 and 4, the unconditioned ones, the occlusion and the late IPC, there was really no difference. Does that surprise you in this preparation?

Dr Toumpoulis. Actually it does not, when we combine these results with our previous studies. We previously showed that all animals had normal outcomes after 35 minutes of aortic occlusion in the early IPC group. However, animals with late IPC and 35 minutes of aortic occlusion showed impairment in outcomes, both in Tarlov scores and in inflammation and number of neurons. The final results of this study confirmed that superiority.

Dr Pigula. So the difference from your earlier study was the severity of the injury, the duration of the ischemia?

Dr Toumpoulis. Yes. Only early IPC seems to protect the spinal cord after 45 minutes of aortic occlusion.
Dr Randall B. Griepp (New York, NY). This is a nice study, and I compliment you on it. I have two questions. The first is a simple technical one. What was the purpose of the second balloon? Most models of this sort have just clamped the aorta to the left subclavian and not done anything distally.

Second, as you may know, for years we have sacrificed intercostal arteries in clinical resections of thoracic and thoracoabdominal aortic aneurysms, for a period of about an hour or so before we resect the aneurysm. And we've never quite been able to fully explain why our results are as good as they are. The two possible explanations, I think, are opening the collateral network and IPC. And I was just wondering whether you have any thoughts as to whether you're actually doing something at the cellular level or are just dilating the collateral bed. The next day that dilatation had gone away, but 80 minutes later it was still in place.

Dr Toumpoulis. With respect to your first question, I have read the recent published study of your group in which you stated that in the pig at the aortic bifurcation (actually in the pig it is a trifurcation), the role of the median sacral artery seems to be very important. And there's retrograde flow. So to avoid any possibility of retrograde flow, we used the second balloon occlusion catheter at the aortic trifurcation in the pig.

Regarding the protection that IPC is showing in the spinal cord, I don't have know what is the protective mechanism. It was not the purpose of our study to elucidate the mechanism. However, it was important to maintain the systolic arterial pressure under high normal levels for IPC to show its beneficial effect on spinal cord.

And in our previous study, we had 2 animals that were hypotensive during the procedure and during the perfusion interval in the early IPC group, and these animals showed no protection of the spinal cord. So one important thing is to maintain the arterial pressure, as you described in your clinical study, in which you maintained the arterial pressure at high levels. On the other hand, IPC gives the opportunity to the cells to learn the ischemic stress, and then they can be preconditioned to deal with the higher ischemic stress.

Dr G. Hossein Almassi (Milwaukee, Wis). In terms of the correlation to the clinical setting, 45 minutes of crossclamping of the aorta is going to cause injury in human beings. What's the correlation? I take it that we shouldn't go home and say that on the basis of your study we can do preconditioning in humans when we're doing a thoracic aortic aneurysm repair. Is there anything safe there? Because we know 20 or 30 minutes of clamping of the aorta is going to cause some injuries in human beings, so can we get to the second stage of actually doing the repair after preconditioning? Can you elucidate a little more?

Dr Toumpoulis. I think that there is as yet no need to correlate this experiment with the clinical situation. That was not the purpose of this study; we did not intend to transfer these results to the clinical situation. This is only an experimental model, and it is only a tool to study ischemic spinal cord injury. We have just shown that early IPC had a beneficial effect on spinal cord injury relative to late IPC. However, this protection was not complete even in the early IPC group, because there was still a $20 \%$ reduction in the number of neurons. 